\title{
Paradigm shift in the management of type B insulin resistance
}

\author{
Jun Hwa Hong ${ }^{1}$, Hyun Jin Kim ${ }^{2}$, Kang Seo Park ${ }^{1}$, Bon Jeong Ku ${ }^{2}$ \\ ${ }^{1}$ Department of Internal Medicine, College of Medicine, Eulji University, Daejeon, Republic of Korea; ${ }^{2}$ Department of Internal Medicine, \\ Chungnam National University College of Medicine, Daejeon, Republic of Korea \\ Correspondence to: Bon Jeong Ku. Department of Internal Medicine, Chungnam National University School of Medicine, 266 Munhwa-ro, Jung-gu, \\ Daejeon 35015, Republic of Korea. Email: bonjeong@cnu.ac.kr. \\ Provenance: This is an invited Editorial commissioned by the Section Editor Kaiping Zhang (AME College, AME Group, China). \\ Comment on: Klubo-Gwiezdzinska J, Lange M, Cochran E, et al. Combined Immunosuppressive Therapy Induces Remission in Patients With Severe \\ Type B Insulin Resistance: A Prospective Cohort Study. Diabetes Care 2018;41:2353-60.
}

Submitted Oct 29, 2018. Accepted for publication Nov 12, 2018.

doi: $10.21037 /$ atm.2018.11.21

View this article at: http://dx.doi.org/10.21037/atm.2018.11.21

Insulin-resistance is the principal pathogenesis of type 2 diabetes mellitus. The increased insulin resistance impairs insulin secretion from beta cell in pancreas. Insulinresistance combined with minimal insulin secretion triggers type 2 diabetes mellitus. Insulin-resistance is frequently caused by obesity and the associated inflammation. The pathophysiological approach to treatment of type 2 diabetes features management of the insulin-resistance (1). However, rarely, a patient may exhibit extremely high-level insulinresistance and refractory hyperglycemia, despite treatment with multiple oral hypoglycemic agents and high doses of insulin. Severe insulin-resistance is clinically diagnosed when the daily, exogenous insulin requirement is over 2 units per kilogram of body weight or over 200 units in total $(2,3)$. Many medications, including glucocorticoids, atypical antipsychotics, calcineurin inhibitors, protease inhibitors, and oral contraceptives, are associated with severe insulin-resistance. Endocrine disorders (acromegaly, glucagonoma, thyrotoxicosis, Cushing's syndrome, and pheochromocytoma) may also cause severe insulinresistance. It is occasionally possible to define the cause of severe insulin-resistance via a detailed history-taking and physical examination (4). However, if this does not succeed, it may be helpful to consider the syndromes of severe insulin-resistance; these are classified into three types by etiology (Table 1). Type A insulin-resistance is caused by a mutation in the insulin receptor gene INSR, and is thus inherited (5). Type B insulin-resistance is a more clinically severe form of disease caused by the production of antibodies targeting the insulin receptor. The pathogenesis of type C insulin-resistance remains unknown, but may feature impairment of tyrosine kinase activity, compromising the normal binding of insulin to its receptor (6). This form of insulin-resistance is associated with a distinctive clinical phenotype termed hyperandrogenism, insulin resistance, and acanthosis nigricans (HAIR-AN) syndrome. Particularly, patients with type B insulin-resistance are refractory to therapy and experience high-level mortality despite treatment. The aims of treatment are to normalize the blood glucose level, restore the hypercatabolic state, and prevent hyperglycemic complications (including vascular complications and ketosis). However, the levels of insulin required to attain these goals may be very high. Although use of highly concentrated insulin solutions (such as U-500) reduce injection volumes and injection site pain, glycemic control is limited by the fact that peak insulin activity develops 4-6 h post-injection and the duration of action is only $12-14$ h $(7,8)$. Pioglitazone, a peroxisome proliferatoractivated receptor gamma agonist, is an insulin sensitizer reducing insulin-resistance in type 2 diabetes patients (9). However, patients with type B insulin-resistance taking pioglitazone exhibited uncontrolled blood glucose levels and persistent insulin-resistance.

Alternative therapies seek to modulate the autoimmune issues of patients with type B insulin-resistance, and include plasmapheresis (10), intravenous immunoglobulin injection (11), and high-dose steroids. No large placebocontrolled trials have been conducted; the results are confined to case reports and small patient populations (12), and are conflicting. Rituximab, an anti-CD20 monoclonal antibody, 
Table 1 Differential characteristics of the severe insulin-resistance subtypes

\begin{tabular}{|c|c|c|c|}
\hline & Type A & Type B & Type C \\
\hline Prevalence & $1: 100,000 ;$ female predominance & Rare; no prevalence reported & $\begin{array}{l}1-3 \% \text { of females exhibiting } \\
\text { hyperandrogenism }\end{array}$ \\
\hline Inheritance & $\begin{array}{l}\text { Autosomal dominant or autosomal } \\
\text { recessive }\end{array}$ & Not known & Not known \\
\hline Prognosis & Generally, not life-threatening & Mortality over $50 \%$ & Generally, not life-threatening \\
\hline
\end{tabular}

HAIR-AN, hyperandrogenic, insulin-resistant, and acanthosis nigricans; NIH, National Institutes of Health; IV, intravenous.

depletes CD20+ B cells and reconstitutes the peripheral B cell lineage (13). Rituximab in combination with cyclophosphamide and a high-dose pulsed corticosteroid induced remission in insulin-refractory patients, as did a combination of intravenous immunoglobulin and plasmapheresis (14), and corticosteroid therapy (15). Recently, complete remission of type B insulin-resistance after immunotherapy that included rituximab has been described in several case reports (16-18). However, only short-term remission data were presented; long-term data are few in number.

Klubo-Gwiezdzinska et al. conducted a prospective cohort study featuring an immunotherapeutic combination that included rituximab. Long-term (72 months) efficacy and safety were remarkably good (19). Combined immunosuppressive/remission therapy (rituximab, a highdose steroid pulse, and cyclophosphamide) followed by maintenance therapy (azathioprine) was associated with an excellent remission rate $(86.4 \%)$ at an average of 6 months. When on maintenance therapy, the recurrence rate was low (13.6\%) over 72 months. A National Institutes of Health (NIH) report found that the mortality of patients with type B insulin-resistance was $54 \%$ within a mean of 62 months from diagnosis (20). In contrast, all patients treated via combined immunotherapy remained alive for 6 years despite (some) recurrence. Although four immunosuppressive therapies were applied, the incidence of adverse effects was low. No infusionrelated reaction or multifocal leukoencephalopathy was reported, despite the use of rituximab (21). Only one patient developed gross hematuria caused by cyclophosphamide-induced hemorrhagic cystitis (22). Severe neutropenia with an absolute neutrophil count less than $500,000 / \mu \mathrm{L}$ was reported in only one patient; cyclophosphamide was discontinued. Any worsening of hyperglycemia upon pulsed steroid therapy was transient; no severe hypoglycemia developed in any patient.

The type B insulin resistant patient who relapsed after treatment with plasmapheresis exhibited improved glycemic control after rituximab administration. However, uncontrolled glucose and elevated insulin antibody titers, so-called relapse, were encountered 2 years after rituximab treatment. Additional administration of mycophenolate and prednisolone with rituximab re-induced remission in terms of glycemic control and insulin antibody titer (17). According to some previous cases, rituximab has a very high efficacy for inducing initial remission in type B insulin resistant patients, in spite of relapse from the initial treatment modality such as intravenous immunoglobulin or plasmapheresis. Although it is highly effective at inducing remission, maintaining remission with rituximab itself is challenging. Therefore, additional treatments, 
such as mycophenolate, cyclophosphamide, high dose prednisolone, and azathioprine, are needed to maintain the initial remission (12). Protocols for the dose and duration of alternative therapy are not standardized and differ among cases. Klubo et al. applied a relatively coherent treatment protocol to 22 patients (one cycle of rituximab, five consecutive steroid pulses, and additional cyclophosphamide for 6 months). Although many patients were enrolled in the study, further cases using the same treatment protocol are required to establish a standardized combined therapeutic regimen for type B insulin resistant patients. Furthermore, long-term follow up data from treated patients will assess the efficacy and long-term safety of rituximab-based combined chemotherapy.

In summary, rituximab-based combined chemotherapy appears to be a highly effective and safe therapeutic regimen for patients with type B insulin-resistance. The combined chemotherapy shows superior durability to achieve sustained remission over 6 years. It may be possible to change the clinical course of type B insulin-resistance from one that is often fatal to one that is curable. With additional large-size trials and long-term follow up data, rituximabbased combined chemotherapy may become the standard treatment for patients with type B insulin-resistance.

\section{Acknowledgements}

None.

\section{Footnote}

Conflicts of Interest: The authors have no conflicts of interest to declare.

\section{References}

1. DeFronzo RA, Eldor R, Abdul-Ghani M. Pathophysiologic approach to therapy in patients with newly diagnosed type 2 diabetes. Diabetes Care 2013;36 Suppl 2:S127-38.

2. Church TJ, Haines ST. Treatment Approach to Patients With Severe Insulin Resistance. Clin Diabetes 2016;34:97-104.

3. Crasto W, Jarvis J, Hackett E, et al. Insulin U-500 in severe insulin resistance in type 2 diabetes mellitus. Postgrad Med J 2009;85:219-22.

4. Ovalle F. Clinical approach to the patient with diabetes mellitus and very high insulin requirements. Diabetes Res Clin Pract 2010;90:231-42.
5. Parker VE, Semple RK. Genetics in endocrinology: genetic forms of severe insulin resistance: what endocrinologists should know. Eur J Endocrinol 2013;169:R71-80.

6. Globerman H, Karnieli E. Analysis of the insulin receptor gene tyrosine kinase domain in obese patients with hyperandrogenism, insulin resistance and acanthosis nigricans (type $\mathrm{C}$ insulin resistance). Int J Obes Relat Metab Disord 1998;22:349-53.

7. Lane WS, Cochran EK, Jackson JA, et al. High-dose insulin therapy: is it time for U-500 insulin? Endocr Pract 2009;15:71-9.

8. Lalej-Bennis D, Selam JL, Fluteau-Nadler S, et al. Extreme insulin resistance: clinical management by external subcutaneous insulin infusion. Diabetes Metab 1997;23:533-6.

9. Staels B. Metformin and pioglitazone: Effectively treating insulin resistance. Curr Med Res Opin 2006;22 Suppl 2:S27-37.

10. Page KA, Dejardin S, Kahn CR, et al. A patient with type $\mathrm{B}$ insulin resistance syndrome, responsive to immune therapy. Nat Clin Pract Endocrinol Metab 2007;3:835-40.

11. Zhang S, Wang G, Wang J. Type B insulin resistance syndrome induced by systemic lupus erythematosus and successfully treated with intravenous immunoglobulin: case report and systematic review. Clin Rheumatol 2013;32:181-8.

12. Malek R, Chong AY, Lupsa BC, et al. Treatment of type $\mathrm{B}$ insulin resistance: a novel approach to reduce insulin receptor autoantibodies. J Clin Endocrinol Metab 2010;95:3641-7.

13. Barr TA, Shen P, Brown S, et al. B cell depletion therapy ameliorates autoimmune disease through ablation of IL-6producing B cells. J Exp Med 2012;209:1001-10.

14. Manikas ED, Isaac I, Semple RK, et al. Successful treatment of type B insulin resistance with rituximab. J Clin Endocrinol Metab 2015;100:1719-22.

15. Iseri K, Iyoda M, Shikida Y, et al. Rituximab for the treatment of type B insulin resistance syndrome: a case report and review of the literature. Diabet Med 2017;34:1788-91.

16. Caga-anan G, DeCastro I, Bates JT, et al. Type B Insulin Resistance: A Rare Type of Diabetes Mellitus. AACE Clinical Case Reports 2016;2:e256-9.

17. Coll AP, Thomas S, Mufti GJ. Rituximab therapy for the type B syndrome of severe insulin resistance. N Engl J Med 2004;350:310-1.

18. Hao JB, Imam S, Dar P, et al. Extreme Insulin Resistance From Insulin Antibodies (Not Insulin Receptor 


\section{Page 4 of 4}

Antibodies) Successfully Treated With Combination Immunosuppressive Therapy. Diabetes Care 2017;40:e19-20.

19. Klubo-Gwiezdzinska J, Lange M, Cochran E, et al. Combined Immunosuppressive Therapy Induces Remission in Patients With Severe Type B Insulin Resistance: A Prospective Cohort Study. Diabetes Care 2018;41:2353-60.

20. Arioglu E, Andewelt A, Diabo C, et al. Clinical course of

\section{Hong et al. Management of type B insulin resistance}

the syndrome of autoantibodies to the insulin receptor (type B insulin resistance): a 28-year perspective. Medicine (Baltimore) 2002;81:87-100.

21. Clifford DB, Ances B, Costello C, et al. Rituximabassociated progressive multifocal leukoencephalopathy in rheumatoid arthritis. Arch Neurol 2011;68:1156-64.

22. Martin F, Lauwerys B, Lefebvre C, et al. Side-effects of intravenous cyclophosphamide pulse therapy. Lupus 1997;6:254-7.
Cite this article as: Hong $\mathrm{JH}$, Kim HJ, Park KS, Ku BJ. Paradigm shift in the management of type B insulin resistance. Ann Transl Med 2018;6(Suppl 2):S98. doi: 10.21037/ atm.2018.11.21 